\title{
The Enlightenment of Cognitive Style Differences between Field Dependent and Field Independent Mode on College English Teaching
}

\author{
Xiaoli Wang \\ Department of Foreign Languages, China West Normal University, China
}

\begin{abstract}
Among all cognitive styles, it is field-dependence and field-independence that are the most widely studied and most representative cognitive styles in recent years. To some extent, it is the core of cognitive style. Because it has the longest research history, studied most widely and formed relatively mature measuring methods. College English proficiency will pave the way for graduates in today's increasingly fierce competitive environment. So it is necessary for teachers to pay more attention to college English teaching. Besides, the FD/FI cognitive styles can have a great impact on the memories, thoughts, studies and communications of the students, which contacts closely with college English learning and teaching. They hence deserve further research. Accordingly, the objectives of this paper are to analyze field-dependent and field-independent English learners and their different features in college English listening, grammar, reading, and to point out that, for college English teaching, if the teachers can understand students' differences on cognitive style and use corresponding teaching strategies to lead their cognitive style, the effect of college English teaching will be greatly improved.
\end{abstract}

Keywords: Cognitive style; Field-independent; Field-dependent; College english teaching; Enlightenment

\section{INTRODUCTION}

The way we learn things in general and the particular attack we make on a problem seem to hinge on a rather amorphous link between personality and cognition; this link is referred to as cognitive style. Cognitive style is usually described as a stable and persistent personality dimension which influences attitudes, values, and social interaction. It is a characteristic of cognitive processing which is particular to a certain individual or class of individuals. To be more clearly, cognitive styles refer to the individual's consistent and characteristic predispositions of perceiving, remembering, organizing, processing, thinking and problem solving. As explained above, according to the learner's different tendency, cognitive styles could be divided into the following four types: Field-dependent Type \& Field-independent Type, Reflective Type \& Impulsive Type, Global Type \& Particular Type, Left-brain Type \& Right-brain Type. Among all the types of cognitive style, the dimension of field-dependence and field-independence, which reflects one's mode of perceiving, remembering and thinking, has been the most extensively studied with the broadest application to problems of education. When cognitive styles are specifically related to an educational context, such as college English education, where affective and physiological factors are intermingled, they are usually more generally referred to as learning styles, which will especially and definitely influence the students' English proficiency. What's more, it is urgent that college English teaching strategies should change in accordance with learners' individual differences because our focus now have transferred from teachers' "how to teach" to students" "how to learn" and then teachers promote teaching through 
students' learning. In this sense, it is significant for teachers to study how FD/FI influence the college English learning. Moreover, corresponding teaching strategies based on the differences between FD and FI should be adopted to improve the quality of college English teaching and then further increase the efficiency of English learning.

\section{Characteristics OF FD/FI Learners}

According to Witkin, FD/FI cognitive style is a value-neutral concept and the ability to distinguish key elements from a distracting or confusing background is its character, and FD/FI cognitive style has a close relationship with the characteristics of individual functioning in social, intellectual, and perceptual domains of human behavior, in other words, FD/FI cognitive style is the extent to which a person perceives parts of a field discrete from the surroundings rather than embedded in it as a whole (Witkin eta1.1977). FD cognitive style is a learning style where learners have a tendency of treating the whole learning task that includes many items. FI learners can identify or focus on particular items and tend not to be distracted by other items in the background or context.

Witkin began his research on the application of style to language learning through the concept of FD/FI in later 1962. According to his researches, he has proposed that a contrast can be made between analytic and holistic individuals. He said that former groups could be considered as analytic. This group faced with a situation in which decision-making is necessary, and could be more able to separate a problem into components. What's more, they can decompose a whole into the constituent elements, and focus on the constituents independently of one another. On the contrary, holistic individuals prefer to begin with the whole picture, process information simultaneously and look for patterns. In addition, they always did their best for unity between events or objects and they are more likely to think by means of analogies. What's more, they are likely to make great use of metaphors and similes in drawing conclusions. However, they have disadvantages. It is that they cannot easily perceive the specific information embedded in the whole passage.

\subsection{Features of FD Learners}

A field dependent learner is one who processes information globally. This kind of learner is less analytical, not attentive to detail, and sees the perceptual field as a whole. This whole resists analysis or decomposition. Students who are field dependent may prefer group projects and they need more explicit instructions and when material to be learned is disorganized. Field dependent learners are more socially oriented, and therefore they respond more to reward and punishment.

According to Witkin and Goodenough (1981), field dependent learners pay more attention on social cues, like to be with others and seek learning and vocational experiences that put them in contact with people. The more field dependent person is reliant on external referents as a result of their amount of differentiation of self from non-self. Dependent learners rely more on the teacher and peer support. When field dependents interact with stimuli, they find it difficult to locate the information. They are seeking because other types of information mask what they are looking for. Field dependent learners perform less well on formal operations tasks than do field independent learners.

\subsection{Features of FI Learners}

A field independent person, on the other hand, can easily break the field down into its component parts. He/she is typically not influenced by the existing structure and can make choices independent of the perceptual field. Field independent persons spend more on self and seem readily to learn material that has a social context. Field independent learners appear to be more adept to the unstructured classroom than their field dependent counterparts. Field independence appears to result in a greater development of cognitive restructuring skills. They will prefer situations that allow them freedom in 
working toward their goals and solving problems. Field independents find it easier to recognize and select important information from its surrounding field. When information is presented in an ambiguous, unstructured format, the field independent will impose his/her own structure on the information. In contrast, the field dependent will attempt to understand and learn that information as it is presented and without restructuring it.

To describe the characteristics between field dependent and field independent learners in detail, a table is listed below:

\begin{tabular}{|c|c|c|}
\hline & FD & FI \\
\hline \multirow[b]{2}{*}{ Perception } & $\begin{array}{l}\text { Rely on surrounding perceptual field or } \\
\text { context for information }\end{array}$ & $\begin{array}{l}\text { Perceive objects as separate from the field or } \\
\text { context }\end{array}$ \\
\hline & $\begin{array}{l}\text { Experience their environment in a fashion } \\
\text { by conforming to the prevailing context }\end{array}$ & $\begin{array}{l}\text { Scan an item from the field in an analytical } \\
\text { fashion }\end{array}$ \\
\hline Problem solving & $\begin{array}{l}\text { Accept other people's view before making } \\
\text { a judgment }\end{array}$ & $\begin{array}{l}\text { Solve problems independently based on } \\
\text { factual information }\end{array}$ \\
\hline \multirow[b]{3}{*}{ Human relations } & Are strongly interested in people & Tend to be socially detached \\
\hline & $\begin{array}{l}\text { Get closer to the persons who they are } \\
\text { interacting with and are emotionally open }\end{array}$ & $\begin{array}{l}\text { Show tendency to physical and psychological } \\
\text { distance }\end{array}$ \\
\hline & Are socially oriented & Are task oriented \\
\hline \multirow{3}{*}{ Motivation } & $\begin{array}{l}\text { Seek approval from authority figures } \\
\text { through praise }\end{array}$ & $\begin{array}{l}\text { Experience independence from authority } \\
\text { which leads to reliance on their own standards }\end{array}$ \\
\hline & $\begin{array}{l}\text { Are extrinsically motivated by externally } \\
\text { designed goals }\end{array}$ & $\begin{array}{l}\text { Are intrinsically motivated and have } \\
\text { self-designed goals }\end{array}$ \\
\hline & Are affected by criticism & Are less affected by criticism \\
\hline \multirow{4}{*}{ Learning } & Like to work with others & Prefer to work independently \\
\hline & $\begin{array}{l}\text { Prefer to learn material with social context } \\
\text { and relevance to own experience }\end{array}$ & Interested in concepts for their own sake \\
\hline & Want organization to be provided & Can self-structure situation \\
\hline & $\begin{array}{l}\text { Use a spectator approach to concept } \\
\text { attainment }\end{array}$ & $\begin{array}{l}\text { Use hypothesis-testing approach to attain } \\
\text { concept }\end{array}$ \\
\hline
\end{tabular}

(cited in Witkin et al., 1977)

\section{Different Characteristics of FD/Fi students in the Process of Listening, GRAMMAR, READING}

\subsection{Features of FD/FI Students in Listening}

The two cognitive styles of FD/FI are closely related to students' English listening learning. As we already know, Field independent learners are not good at communication with people, and like independent study, independent thinking. So they prefer English articles on Natural Science in the process of listening and are good at listening to the general meaning of exposition. Field dependent learners prefer group connection and are more inclined to those articles, especially the narrative, which can develop one's ability of social communication. Both FI and FD correlate negatively with listening proficiency. Besides, it is obvious that there exists a difference between these two coefficients, indicating that the intensity of negative correlation between FD cognitive style and listening proficiency is less recognizable, and thus justifies the statement that field dependent learner may behave better in listening. 
Here the reasons may lie in three aspects. First of all, listening contents tend to be understood in concrete situation or contexts. In relying on the contexts of listening, field dependent learners are obviously more capable than field independent learners, who may focus their attention on specific words or expressions and ignore the concrete contexts. Secondly, listening proficiency tend to be closely related to the proficiency of oral English, and still this may be advantage of field dependent language learners. Thirdly, it is estimated that maybe learners with field mixed style will have a higher level of listening proficiency.

\subsection{Features of FD/FI Students in Grammar}

Grammar is mainly about the laws of vocabularies and sentences, all isolated language items in language teaching. Also, grammar is a series of fixed regulations which instruct learners the right way to use words and construct sentences. Field independent are characteristic of being able to behave better dealing with the isolated items in a certain field. In this sense, FI learners should be better at mastering grammar than FD learners. However, in the term of examination, cloze test and Chinese-English translations are categorized into the field of grammar and cloze test particularly demands to some extent the ability of considering things in their contexts. This may justify why there also exists a positive correlation between FD cognitive style and grammar proficiency. So there is no absolute evidence or arguments for which one is doing better in grammar learning. As far as college English teaching's concerned, it is essential that our teachers should adopt effective and efficient teaching methods to make students master grammar which is always tedious on the basis of getting to know the differences between field dependent and field independent in English grammar learning.

\subsection{Features of FD/FI Students in Reading}

FD learners are found to perceive information in a global way rather than decompose situation into components and tend to make judgment according to external reference. They usually resort to their preexisting background knowledge (external clues) rather than the reference within the text itself (internal reference) and form overall prediction about the whole text when start reading. But FI learners who decompose a whole context into components and then they tend to be detailed focused and code with the constituents separate from one to another. The correlation between FD/FI cognitive style and reading proficiency has been researched most often, and there are many conclusions and assumptions put forward. And agreement is nearly achieved that FI-oriented language learners tend to have a higher level of reading proficiency and the correlation is significantly eminent.

The possible reasons are then to be introduced as follows. First, in the term of examination, reading comprehension is the kind of test item that is marked most. In traditional English language test papers this is almost always the case, because reading is a very important part in language learning. Second, field independent learners tend to learn better in classroom learning while field dependent learners may behave better in an open way. Considering the importance of reading proficiency, field independent learners tend to devote large amount of their time to reading practice and comprehension. And most efforts are made to improve reading proficiency in order to improve their language learning. Third, reading in its nature demands the understanding of vocabularies and sentences. In traditional language classroom in China, where grammar and reading are emphasized, field independent learners will undoubtedly learn better than field dependent language learners.

\section{The Enlightenment on College English Teaching}

\subsection{To be Aware of the FD/FI Cognitive Style}

FD/FI cognitive style exerts influence upon students' ways to process information, thus it deserves teachers and students to pay attention to the different characteristics of FD/FI cognitive style. Only 
when they get a full picture of the FD/FI cognitive style can students make great progress with the help of the advantages of cognitive style.

As for Students, they should be aware of FD/FI cognitive style of their own and learn about their cognitive style features. As both FD and FI cognitive styles have advantages and disadvantages, they have to overcome the disadvantages of the each cognitive style and take advantage of the favorable traits of their own cognitive style. They should know to what extent he or she belongs to certain kind of FD/FI cognitive style. They can know their own FD/FI degree or tendency either by self-reflection or self-examination according to FD/FI theory or taking the FD/FI degree test. If students know their FD/FI cognitive style, they can utilize their advantages of cognitive style in order to make progress and seek some compensatory strategies to overcome the limitations caused by their FD/FI degree.

As far as teachers are concerned, they are expected to get students to adapt to their classroom learning well. They have to have a general understanding of their students and differentiate each student's FD/FI cognitive style and adopt the best teaching methods. Teachers can briefly introduce FD/FI cognitive style to students and help them analyze their FD/FI tendency according to which student will set learning goals, makes study plans, selects appropriate learning strategies. Moreover, teachers should get students bear in mind that what a good English learner do in the process of learning and make efforts to overcome the bad learning habits caused by cognitive style. It is of great importance for learners to get useful feedbacks from their own learning process.

\subsection{Teaching Strategies for FD Learners and FI Learners}

After knowing students FD/FI cognitive style, it is essential for college English teachers to know how to help students overcome the disadvantages brought by FD/FI cognitive style when they are carrying out different learning tasks. FD/FI is one of a stable psychological feature of human cognitive styles, but it is changeable in some situations. Students are expected to overcome the disadvantages of their FD/FI and train themselves to be more flexible learners under the help of teachers.

For FD learners, Firstly, college English teachers should be aware of the fact that FD learners have a tendency of cooperation. So when adopting teaching strategy, teachers should lay more emphasis on cooperation and collectivism in learning process. Cooperative tasks may result in FD learners' losing face or embarrassment. At the same time, FD learners don't like to be singled out from the rest of the class so teachers should treat the whole class as a whole group. Therefore, teachers should praise less frequently than they do FI learners. FD learners are sensitive to teachers' opinion on them. So if the teachers feel it quite necessary to praise or criticize some students, it is better to praise or criticize them privately rather than in public. Meanwhile, teachers should give a detailed explanation on concepts, learning processes and present curriculum design.

Secondly, FD learners tend to be more sensitive to learning environment than FI learners do. They believe that they belong to the whole class and they are accepted in the school. They try to maintain a positive relationship with their teachers and peers. If not, they will feel discouraged. If they feel alienated and isolated, they might become less motivated to learn. If teachers show strong interest in their responses and give FD learners more encouragement, they will perform better. When teaching FD students, teachers can lay emphasis on them and create a sense of belonging to particular community for FD learners and try to become good friends of these students. As long as they establish firm friendship, FD students' motivation in learning will be stimulated strongly.

FI learners, however, are better at separating easily the key details from an ambiguous context by using of analysis. Field independent learners tend to be less sensitive to the social context. They tend to learn alone, to solve problems independently, to compete with others and to be singled out praised 
individually. Their feelings are seldom sensitive to others' and they tend to be socially detached, less depend on teachers, keep a physical and psychological distance from teachers and their peers and like to try new tasks without the teachers' help.

What's more, FI learners prefer to learn through competition with others. So teachers should advocate competition among field independent learners. They should be given more opportunities to do researches individually, to make up their own plans, to think solutions by themselves. Teachers needn't give them help unless field independent learners get into trouble in solving problems and seek help from teachers. Since they prefer to use hypothesis-testing approach to attain concepts and they need to use trial and error method to explore their issues.

\section{Conclusion}

The study of field dependence and field independence provides great help for college English teaching, so that teachers can teach students in accordance with their aptitude in the teaching and have a definite object in view. On the one hand, teachers should adjust their teaching methods to their students' cognitive styles and on the other hand teachers can train students to adopt different language learning methods to improve their language learning efficiency. College English teachers should adopt correct and scientific methods to distinguish the field dependent students from the field independent students in the process of college English teaching. Students with different cognitive styles should be given different teaching ways, so that their ability of listening and reading can be greatly improved. At the same time, college students' ability of language acquisition would be enhanced, too. Therefore, the foreign language teaching should attach great importance to promoting students' balance of these two kinds of cognitive style to realize the real quality education and promote the all-round development of students.

\section{REFERENCES}

[1] Hansen, Jacqueline and Stanstield, Charles. The Relationship of Field Dependent-independent Cognitive Styles to Foreign Language Achievement [J]. Language Learning, 1981. 31: 349- 367.

[2] Naniman, N., Frohlich, M., Stern., H.H. and Todesco, A. The Good Language Learner [M]. Toronto: Ontario Institute for Studies in Education.1978.

[3] Roberts, C. and Chapelle, C. Ambiguity Tolerance and Field Independence as Predictors of Proficiency in English as a Second Language [J].Language Learning.1986.36: 27- 45.

[4] Witkin, H.A. \& Goodenough, D.R. Cognitive styles: Essence and origins [M]. New York: International Universities Press, 1981.

[5] Witkin, H.A., Oltaman, P. K, Raskin, E\& Karp. S. D. A Manual for the Embedded Figures Test. Palo Alto. Carlif. : Consulting Psychologists Press.1971.

[6] Witkin, H.A, Moore, C., Goodenough, D. \& Cox,,P. Field-Dependent and Field-Independent Cognitive Styles and Their Educational Implications. Review of Educational Research. 1977(47): $1-64$.

[7] Tennant, M. Psychology and Adult Learning [M].London:Routeledge.1988.

[8] R.T.Pithers. Cognitive Learning Style: a review of the field dependent-field independent approach. Journal of Vocational Education and Training. Volume 54, Number 1, 2002

[9] Goth, C.C, M. 2000. A cognitive perspective on language learners' listening comprehension problems [M]. System 28:55-75.

[10] Abraham, R. 1985. Field independence and dependence and the teaching of grammar [J]. TESOL Quarterly, 20:689-702. 
The Enlightenment of Cognitive Style Differences between Field Dependent and Field independent Mode on College English Teaching

[11] Salmani-Nodoushan, M.A .2007. Is field dependence or Independence a predicator of EFL reading performance? [M]. TESL Canada Journal, 24(2), 82-108.

[12] Frank B.M. \& Davis J.K. 1982. Effects of Field-independence Match or Mismatch on a communication Task [J]. Journal of Educational Psychology, (74): 23-31

[13] Reid, J. M. 2002. Learning styles in the ESL/EFL Classroom [M]. Beijing: Foreign Language Teaching and Research Press.

[14] Dong Qian.2004.Cognitive Styles in Language Teaching. M.A. Thesis. Chongqing University.

[15] Andrew D, Cohen. 2000.Strategies in Learning and Using a Second Language [M]. Beijing: Beijing Foreign Language Teaching and Research Press.

\section{AUTHOR'S BIOGRAPHY}

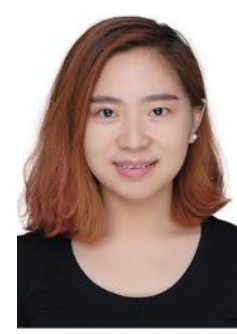

Xiaoli Wang is 26 years old and she is postgraduate from China West normal University in Nanchong, sichuan, China. Her major is Curriculum and Pedagogy (orientation: English). 